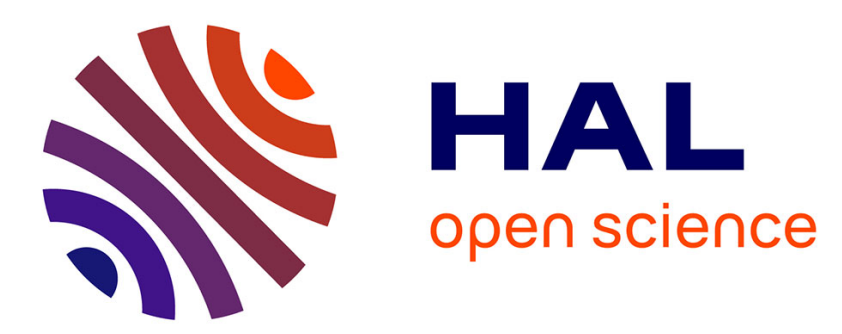

\title{
Complex shape forming of flax based woven fabrics. Analysis of the yarn tensile strain during the process.
}

Pierre Ouagne, Damien Soulat, Christophe Tephany, Julien Moothoo, Samir Allaoui, Gilles Hivet, Davy Duriatti

\section{- To cite this version:}

Pierre Ouagne, Damien Soulat, Christophe Tephany, Julien Moothoo, Samir Allaoui, et al.. Complex shape forming of flax based woven fabrics. Analysis of the yarn tensile strain during the process.. Key Engineering Materials, 2012, 504-506, pp.313-318. hal-00772658

\section{HAL Id: hal-00772658 https://hal.science/hal-00772658}

Submitted on 13 Jan 2013

HAL is a multi-disciplinary open access archive for the deposit and dissemination of scientific research documents, whether they are published or not. The documents may come from teaching and research institutions in France or abroad, or from public or private research centers.
L'archive ouverte pluridisciplinaire HAL, est destinée au dépôt et à la diffusion de documents scientifiques de niveau recherche, publiés ou non, émanant des établissements d'enseignement et de recherche français ou étrangers, des laboratoires publics ou privés. 


\title{
Complex shape forming of flax based woven fabrics. Analysis of the yarn tensile strain during the process.
}

\author{
P. Ouagne ${ }^{\text {a1 }}$, D. Soulat ${ }^{\text {b2 }}$, C. Tephany ${ }^{\text {c1 }}$, J. Moothoo ${ }^{\text {d1 }}$, S. Allaoui ${ }^{11}$, G. \\ Hivet $^{f 1}$, D.Duriatti ${ }^{33}$ \\ ${ }^{1}$ Institut PRISME/MMH, Université d'Orléans, 8 rue Léonard de Vinci 45072 Orléans, France. \\ ${ }^{2}$ Gemtex, ENSAIT Roubaix 2, Allée Louise et Victor Champier, BP30329, 59056 Roubaix, France. \\ ${ }^{3}$ Groupe Depestele - BP 21, 14540 Bourguebus - France
}

\begin{abstract}
apierre.ouagne@univ-orleans.fr, ${ }^{b}$ Damien.soulat@ensait.fr, ${ }^{\circ}$ Christophe.tephany@etu.univorleans.fr, ${ }^{d}$ julien.moothoo@univ-orleans.fr, ${ }^{\circ}$ samir.allaoui@univ-orleans.fr, ${ }^{\dagger}$ gilles.hivet@univorleans.fr, ${ }^{9}$ dduriatti@depestele.com
\end{abstract}

Keywords: Composites, natural fibres, flax fabric, sheet forming, In situ measurements, biaxial tension

\begin{abstract}
A flax fibre plain weave fabric has been used to form a complex tetrahedron shape. The global shape has been obtained. Even if no apparent defects are visible when observing the yarns, the strain of the tightest yarns of the preform has been measured and compared to the biaxial strains of the fabric determined independently of the process. The results show that the strains in the yarns close to the triple point of the shape (top of the tetrahedron) are higher than the strain at failure. This could lead to local lack of fibre density and to possible zones of weakness for the composite part. It is therefore necessary to increase the tensile performances of the yarns constituting the fabric.
\end{abstract}

\section{Introduction}

Natural fibres have long been considered as potential reinforcing materials or fillers in thermoplastic or thermoset composites. Numerous studies deal with the subject [1-6]. Natural fibres are particularly interesting because they are renewable, have low density and exhibit high specific mechanical properties. They also show non-abrasiveness during processing, and more importantly biodegradability. A large amount of work has been devoted to identify the tensile behaviour of individual fibres or group of few fibres of different nature and origin [7-10]. However, few studies deal with the subject of the mechanical behaviour of fibre assemblies and particularly analyze the deformability of these structures.

To manufacture high performance composite parts, it is necessary to organise and to align the fibres. As a consequence, aligned fibres architectures such as unidirectional sheets, non-crimped fabrics and woven fabrics (bidirectional) are usually used as reinforcement.

In the Liquid Composite Moulding (LCM) family, the Resin Transfer Moulding, (RTM) process has received a large attention in the literature [11] and particularly the second stage of the process dealing with the injection of resin in preformed dry shapes and the permeability of the reinforcements [12-13]. The first stage of this process consists in forming dry reinforcements. In case of specific double curved shapes, woven fabrics are generally used to allow in plane strain necessary for forming without dissociation of the yarns.

The modification of the yarn orientation and local variations of fibre volume fraction have a significant impact on the resin impregnation step as the local permeabilities (in-plane and transverse) of the reinforcement may be affected [14-15]. In the most severe cases, the ply of fabric can wrinkle or lose contact with the mould, hence severely reducing the quality of the finished product [16]. Consequently the quality of the preform is of vital importance for the final properties of the composite part. 
Several experimental devices have been set up to investigate the deformation modes and the possible occurrence of defects during forming of textile reinforcements. Hemispherical punch and die systems were particularly studied because the shape is rather simple, it is doubled curved and because it leads to large shear angles between the yarns [17-19]. In this paper, an experimental device is presented to form severe shapes. As an example, tetrahedron geometry is considered as it is much more difficult to form than hemispherical shapes especially if the radiuses of curvature are small.

This paper therefore proposes to analyse the feasibility of forming the mentioned complex shape with natural fibres based woven fabric reinforcements. A special attention is given on the tensile behaviour of yarns and fabrics in relation to the in situ measured tensile strains because natural fibre tows may be subject to failure during complex shape forming and this could lead to a lack of homogeneity for the final composite part. A discussion upon the optimisation of the process parameters as well as the optimisation of the yarns constituting the fabric to improve the formability of flax based woven reinforcements will be presented.

\section{Experimental setup}

A device specifically designed to analyze the local strains during the forming of reinforcement fabrics [20] is presented on Figure 1.a. The mechanical part consists of a punch/open die couple and a classical blank holder system. The die is open to allow the measurement of the local strains during the process with the cameras associated to marks tracking technique. The motion of the punch is given by a piloted electric jack. Nine independent blank holders associated to pneumatic jacks can be activated under the woven flat fabric. Dimensions, positions, and specifically variable pressure on each of these blank holders can be easily changed to investigate their influence on the quality of the final preform. This device has been developed to preform different shapes. Severe double curved shapes containing faces, edges and triple points at the intersection of the edge are considered. The tetrahedron punch used in this work is presented on figure 1.b.

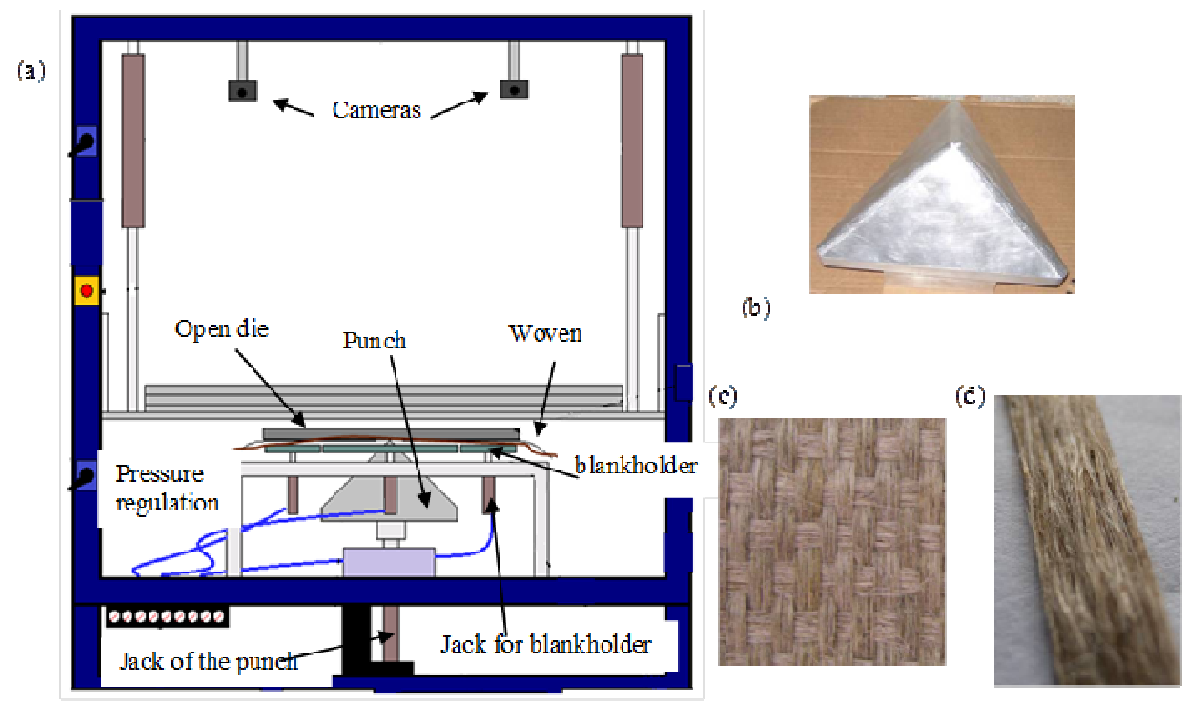

Figure 1: (a) Description of the device. (b) Tetrahedron punch. (c) Flax fabric (d) Flax yarn.

A biaxial tension device has also been used to characterize the tensile behavior of the considered flax fabric. The description of the device as well as the procedure of the test is described in $[21,22]$

\section{Results}

Materials properties and global preform analysis

The flax fabric (Figure 1.c) used in this study is a plain weave fabric which areal weight is of about $625 \mathrm{~g} / \mathrm{m}^{2}$ manufactured by the Groupe Depestele (France). The fabric is not balanced. This 
fabric is constituted of continuous yarns (figure 1.d). Generally, when natural fibres are considered, twisted yarns are elaborated to increase its tensile properties. Indeed, as discussed by Goutianos et al. [23] sufficient tensile properties of the yarns are necessary for these ones to be considered for textile manufacturing or for processes such as pultrusion or filament winding. In this study, the flax yarns used to elaborate the plain weave fabric are un-twisted and exhibit a rectangular shape. The fibres or groups of fibres are slightly entangled to provide a minimum rigidity to the yarns. This geometry has been chosen as it generates low bending stiffness yarns, therefore limiting the crimp effect in the fabric and therefore limiting empty zones between yarns. It has also been chosen because fabric manufactured from highly twisted yarns exhibit low permeability preventing or partially preventing the use of processes from the LCM (Liquid Composite Moulding) family. Untwisted yarns have also been chosen because manufactured composites display better mechanical properties than composites made with twisted yarns [24].

At the local scale, an analysis of the shear angles [25] of the studied face shows that the values are relatively homogeneous and below the locking angle. It has also been shown that buckles defects may take place during the process [26]. Moreover, due to the fact that the flax fabric studied in this work is made with untwisted yarns, local failure may take place without visible evidence as this failure is due to local movements between fibres. Investigations are therefore carried out in this way.

An initial square specimen of the flax fabric is positioned with six blank holders placed on specific places around the tetrahedron punch. On each of them a pressure of two bar is applied. The maximum depth of the punch is $160 \mathrm{~mm}$. At the end of the forming process, an epoxy resin spray is applied to the preform so that the shape is fixed in its deformed state.

Visually, some yarns on the preform seem to be very tight. This is particularly the case of the vertical yarns passing by the triple point (top of the tetrahedron). A local analysis of the tensile strains using a mark tracking method is carried out on those yarns to investigate if failure strain has not been overcome.

Figure 2 shows the position of the tested yarns and the place between which the strain was measured. Figure 3 shows the values of the strains measured on the five considered yarns for one face of the tetrahedron shape. The results show that the strain rises in a non uniform way during the sheet forming process. At the beginning of the test, no strain is observed as the punch is not in contact with the fabric. Once in contact, the strain in the different yarns rises in a regular manner up to values above which the strain increases with a lower slope. Figure 3 also shows that the strains measured on the yarns passing by or close to the triple point (top of the tetrahedron) are higher than the other ones. Moreover, the tensile strain decreases as a function of the increasing distance from the triple point. A ratio of $1 / 2$ is observed between the strain measured at the end of the test for yarn 5 and the strain measured on yarn 1.

The maximum strain values measured at the end of the forming process indicated that these ones are all within the range 5-9.5\%. These values seem to be relatively high in comparison to values evaluated for glass fibre fabric [21] and it is therefore important to investigate the mechanical behaviour of the fabric independently of the process to find out if local failure in the yarn took place during the forming test. Local failure in the yarn causes local movements of the fibres within the yarn, and this may lead locally to lower fibre density. This can certainly be a problem for the final composite part if the fibre density is not kept homogeneous as these places could be zones of weakness. 


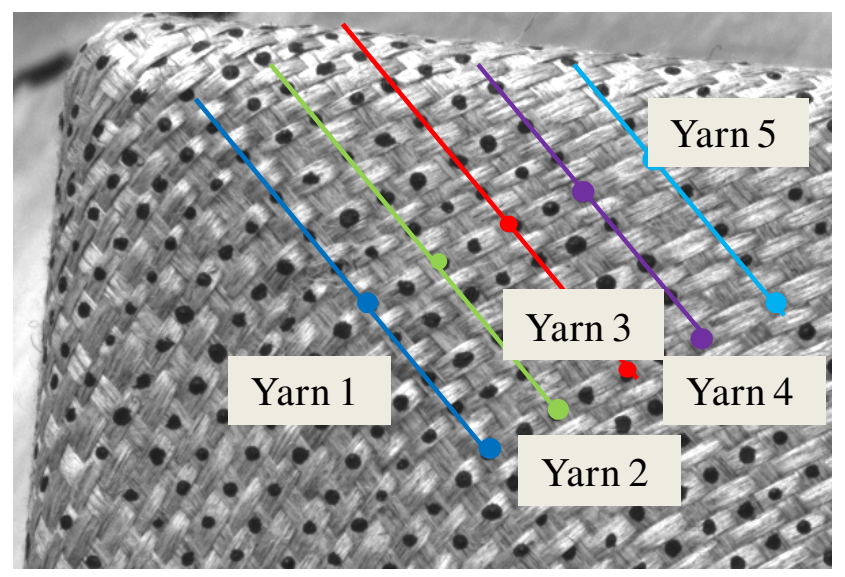

Figure 2 Position of the tested yarns

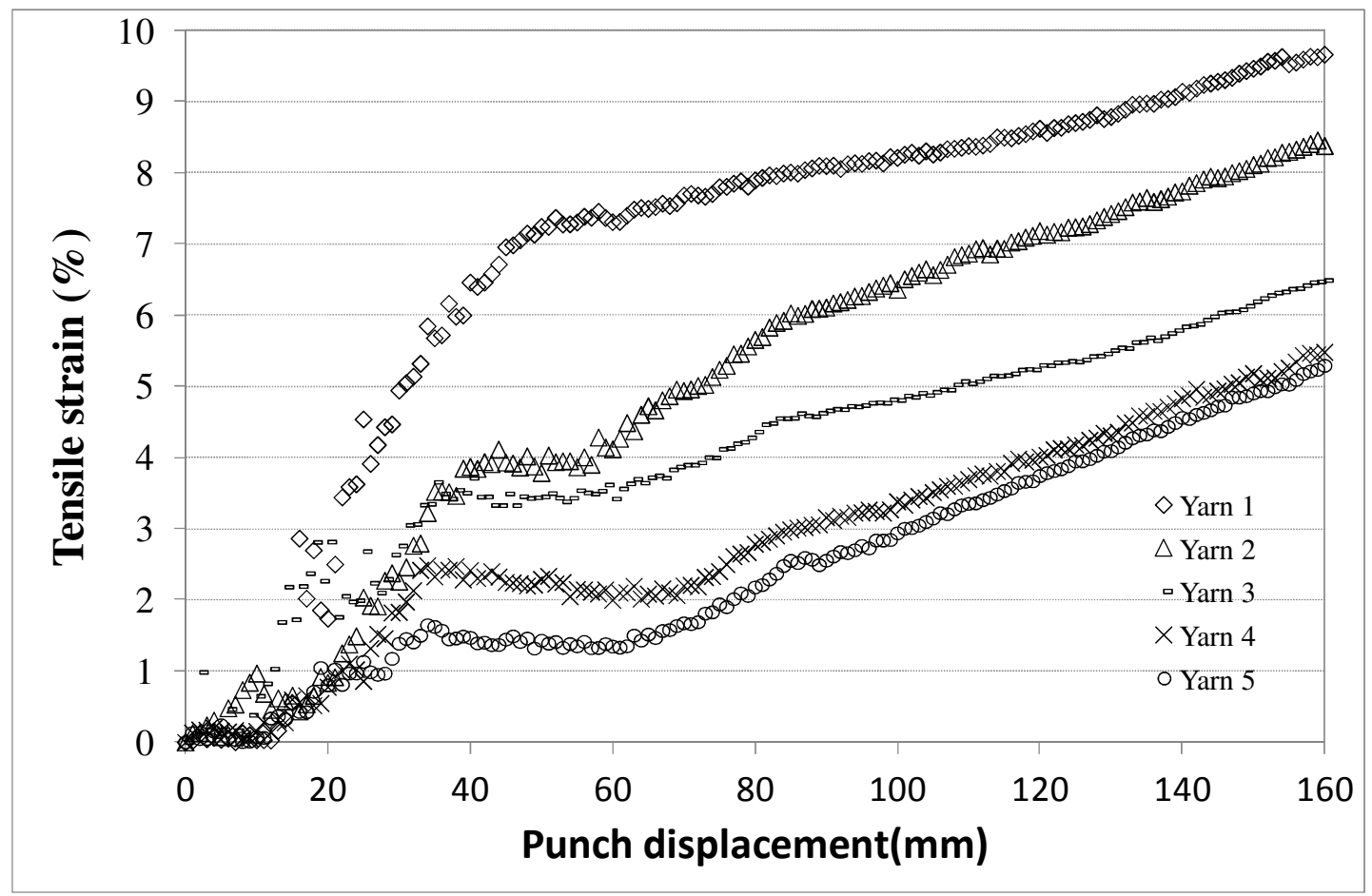

Figure 3: Strain evolution in vertical yarns during the sheet forming process

Biaxial tests were carried out to study the tensile behaviour of the flax fabric. The results showing the biaxial behaviour of the fabric in the weft direction are presented in Figure 4 for different values of the parameter $k_{t}$. The parameter $k t=\varepsilon_{t} / \varepsilon_{c}$ is defined as the ratio between the strain in the weft direction over the one in the warp direction. The results show that an increasing value of $k_{t}$ leads to higher strain in the weft yarns. This means that the crimp effect decreases in this case. The crimp effect is the lowest in the case of the unidirectional test $\left(k_{c}=\varepsilon_{c} / \varepsilon_{l}=0\right)$.

Figure 4 indicate that the maximum failure strain is obtained in the case of the uniaxial test. This phenomenon is normal and is due to the crimp effect. The maximum strain to failure is observed for the case of the uniaxial test $\left(k_{C}=0\right)$. For all the considered cases, the failure strain is lower than 4.5\%. These values are much lower than the ones measured on the tetrahedron face (Figure 2). It is therefore probable that failure occurs in the tighter yarns of the face during the process.

In a general way, the biaxial tensile behaviour of the fabric is very similar to the ones observed on woven fabrics made from glass or carbon fibres [21, 22]. Even if the yarns are not constituted with continuous fibres, the entanglement between the fibres provides a sufficient continuity to the yarn so that this one behaves like a homogeneous entity. 


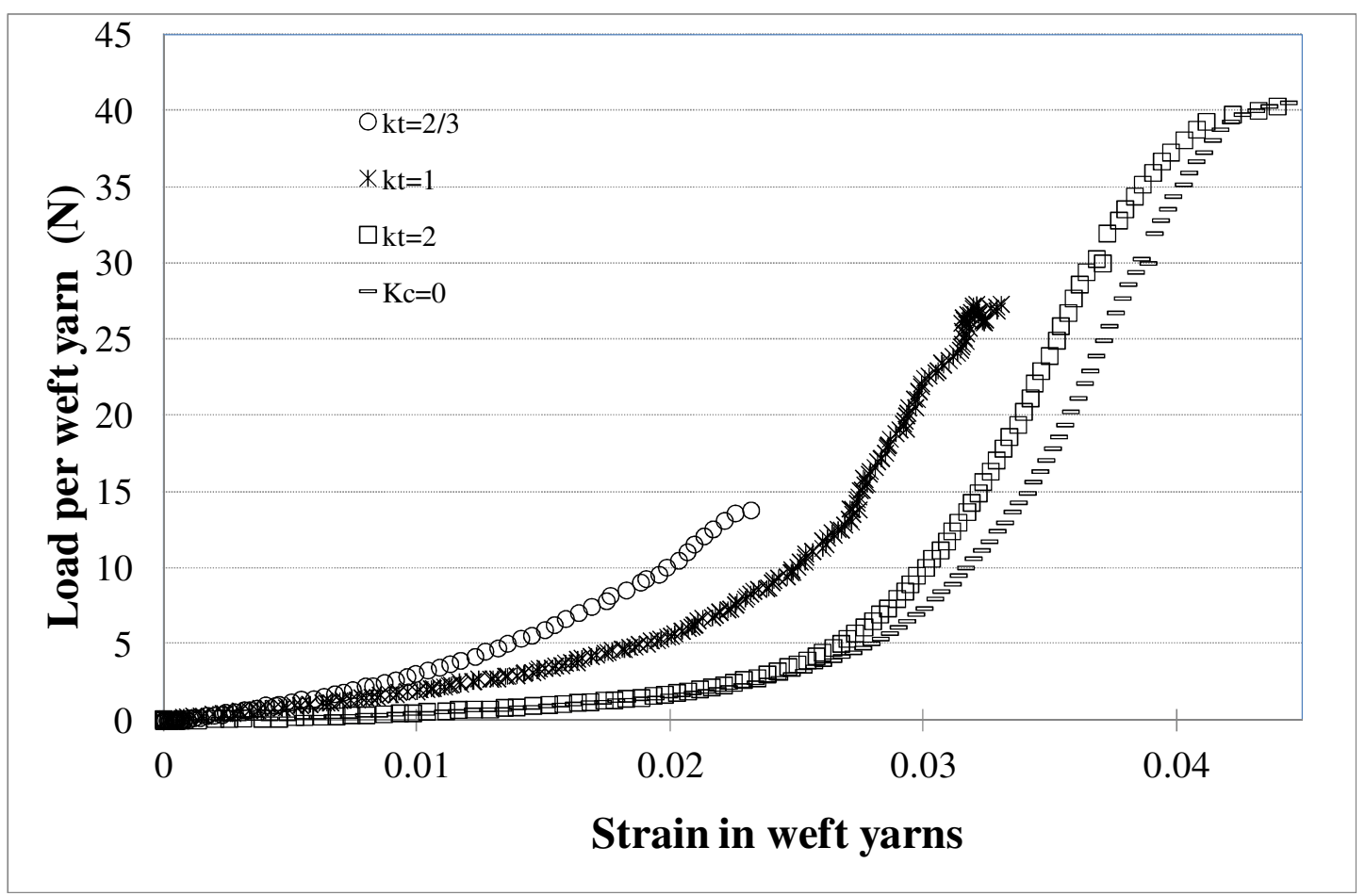

Figure 4: Tensile behaviour of the weft yarns during a biaxial test

\section{Discussion}

The failure resistance of the yarns constituting the studied flax fabric is relatively low. This needs to be kept in mind especially when the fabric is submitted to consequent loads such as the ones taking place during the forming of the tetrahedron shape. It would therefore be interesting to manufacture yarns with higher resistance in tension without twisting the fibres in order to avoid local lack of fibre density. A way of improvement consists in using the longest fibres produces by the flax stem. A length of about $500 \mathrm{~mm}$ would probably be suitable. In this case, the loads involved during the sheet forming process are accommodated by longer fibres and does not as much depend on the bonding or the entanglement between these ones.

\section{Conclusions}

A flax fibre plain weave fabric has been used to form a complex tetrahedron shape. The global shape has been obtained. Even if no apparent defects are visible when observing the yarns, the strain of the tightest yarns of the preform has been measured and compared to the biaxial strains of the fabric determined independently of the process. The results show that the strains in the yarns close to the triple point of the shape (top of the tetrahedron) are higher than the strain at failure. This could lead to local lack of fibre density and to possible zones of weakness for the composite part. It is therefore necessary to increase the tensile performances of the yarns constituting the fabric.

\section{References}

1. La Mantia F.P., Morreale M. "Green composites: A brief review." Composites Part A, 42 (2011), 579-588.

2. Satyanarayana K. G. , Arizaga G. G.C., Wypych F. "Biodegradable composites based on lignocellulosic fibers-An overview" Progress in Polymer Science, 34 (2009), 982-1021

3. Biagiotti J., Puglia D., Kenny J. M. "A Review on Natural Fibre-Based Composites-Part I" Journal of Natural Fibers, 1: 2 (2004), 37 - 68.

4. Puglia, D. , Biagiotti, J. and Kenny, J. M. 'A Review on Natural Fibre-Based Composites—Part II',

Journal of Natural Fibers, 1: 3 (2005), 23 - 65. 
5. Pandey J. K., Ahn S. H., Lee C. S., Mohanty A. K., Misra M. "Recent Advances in the Application of Natural Fiber Based Composites" Macromolecular Materials and Engineering, 295 (2010), 975-989.

6. Ouagne P., Bizet L., Baley C., Bréard J. "Analysis of the Film-stacking Processing Parameters for PLLA/Flax Fiber Biocomposites". Journal of Composite Materials, 44 (2010), 1201-1215.

7. Baley C. "Analysis of the flax fibres tensile behaviour and analysis of the tensile increase" Composites Part A, 33 (2002), 2143-2145.

8. Bodros E., Baley C. "Study of the tensile properties of stinging nettle fibres" Materials Letter, 62 (2008), 2143-2145.

9. Alawar A., Hamed A.M., Al-Kaabi K.. "Characterization of treated data palm tree fiber as composite reinforcement" Composites Part B, 40 (2009), 601-606.

10. Kim J.T., Netravili A.N. "Mercerization of sisal fibers: Effects of tension on mechanical properties of sisal fibers and fiber-reinforced composites" Composite Part A, 41 (2010), 12451252.

11. Buntain M.J.,Bickerton S. "Modeling forces generated within rigid liquid composite moldings tools. Part A: Experimental study" Composites Part A., 38 (2007), 1729-1741.

12.Lekakou C, Johari B, Norman D, Bader G. "Measurement techniques and effects on in-plane permeability of woven cloths in resin transfer molding" Composites Part A, 27 (1996) 401-408.

13. Ouagne P., Bréard J. "Continuous transverse permeability of fibrous media" Composites Part A, 41 (2010), 22-28.

14. Hammani A., Trochu F., Gauvin R., Wirth S. "Directional permeability measurement of deformed reinforcement" Journal of reinforced plastics and composites, 15 (1996), 552-562.

15. Loix F., Badel P., Orgeas L., Geindreau C. Boisse P. "Woven fabric permeability: from textile deformation to fluid flow mesoscale simulations" Composites Science and Technology, 68 (2008), 1624-1630.

16. Sharma S.B., Sutcliffe M.P.F., Chang S.H.. "Characterisation of material properties for draping of dry woven composite material" Composites Part A, 34 (2003), 1167-1175.

17. Molnar P., Ogale A., Lahr R., Mitschang P. "Influence of drapability by using thermoforming" Composites Science and Technology, 67 (2007), 3386-3393.

18. Li X., Bai S. "Sheet forming of the multy-layered biaxial weft knitted fabric reinforcement. Part 1: On hemispherical surfaces" Composites Part A, 40 (2009), 766-777.

19. Vanclooster K., Lomov S.V., Verpoest I. "Experimental validation of forming simulations on fabric reinforced polymers using an unsymmetrical mould configuration. Composites Part A, 40 (2009), 530-539.

20. Soulat D., Allaoui S., Chatel S. "Experimental device for the 6ptimizati step of the RTM process“. International Journal of Material Forming, 2 (2009), 181-184.

21. Duong Anh Vu. Étude expérimentale du comportement mécanique de renforts composites tissés lors de la mise en forme sur géométries non développables. PhD thesis, University of Orléans, 2008.

22. Boisse P., Gasser A., Hivet G. Analyses of fabric tensile behaviour : determination of the biaxial tension-strain surfaces and their use in forming simulation. Composites Part A 2001;32: 13951414.

23. Goutianos S., Peijs T. "The optimization of flax fibre yarns for the development of highperformance natural fibre composites" Advanced Composite Letters, 12 (2003) 237-241.

24. Goutianos S., Peijs T., Nystrom B. Skrifvars M. "Development of flax based textile reinforcements for composite applications" Applied Composites Materials,13 (2006), 199-215.

25. Ouagne P., Soulat D., Allaoui S., Hivet G. "Mechanical properties and forming possibilities of a new generation of flax woven fabrics". Proceeding of the 10th international conference on textile Composite (Texcomp). 26-28 October 2010, Lille, France.

26. Ouagne P., Soulat D., Hivet G., Allaoui S., Duriatti D. "Analysis of defects during the preforming of a woven flax reinforcement". Advanced Composite Letters, 20 (2011) 105-108. 